\title{
APLICACIÓN DE LA GELULOSA BACTERIANA EN EL DISEÑO DE PRODUCTOS: UN CAMINO A LA SUSTENTABILIDAD
}

\author{
APPLICATION OF BACTERIAL GELLULOSE IN THE DESIGN \\ OF PRODUCTS: A PATH TOWARDS SUSTAINABILITY OF \\ THE LABOR FIELD FOR INDUSTRIAL DESIGN
}

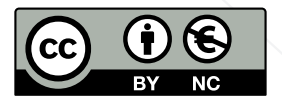

Magíster en Desarrollo Comunitario (2015) por la Universidad Nacional de Loja; (C) Magíster en Diseño de Productos con Mención en Desarrollo e Innovación por la PUCE Sede Ambato; Diseñadora (2004) por la Universidad del Azuay; Diploma Superior en Gerencia Estratégica de Mercadeo (2006) por la Universidad Técnica Particular de Loja; Docente de la Escuela de Diseño Industrial de la PUCE - Sede Ambato, Docente invitada en la Escuela de Arquitectura de la UIDE - Loja (2012), Docente invitada en la Escuela de Comunicación Social de la UTPL. Diseñadora independiente desde el año 2002.

yjimenez@pucesa.edu.ec

orcid.org/0000-0003-0542-768X

Fecha de recepción: 17 de marzo, 2021. Aceptación: 20 de abril, 2021. 


\section{Resumen}

Los niveles de contaminación ambiental provocados por la industria han sobrepasado la capacidad del planeta, en este resultado tiene una responsabilidad importante el diseñador de productos, por ello juega un papel sustancial la ética del diseñador en lo que respecta a la sustentabilidad. Las innovaciones de los biomateriales brindan una oportunidad en esa reivindicación, es así que, la investigación pretende a través de la aplicación de la celulosa bacteriana obtener nuevas posibilidades para la industria del diseño y cuidado del medio ambiente reduciendo los niveles de basura que generan los materiales comunes, debido a que este material celulósico es considerado como sustentable y de carácter renovable. Se planteó el desarrollo de los productos a través de la ruta metodológica ARZ, que coloca los criterios de sustentabilidad como eje de inicio y final al momento de plasmar la necesidad, ideación, venta, uso y desuso del nuevo producto. Como resultado se obtuvo un biomaterial con características fisicoquímicas y mecánicas que permitieron la aplicación en tres series de productos: calzado, carteras y bisutería. La sustentabilidad es la opción del nuevo pensamiento productivo del diseño y de los diseñadores, es decir, crear con responsabilidad social y ambiental.

\section{Palabras clave}

Celulosa bacteriana, biomateriales, diseño ético, diseño sustentable, diseño de producto.

\section{Abstract}

The levels of environmental pollution caused by the industry have exceeded the capacity of the planet. The product designer has an important responsibility for this result, therefore, the ethic of the designer takes a substantial role related to sustainability. The innovations of biomaterials provide an opportunity in this claim, and so, this research aims to obtain new possibilities for the design industry and care for the environment through the application of bacterial cellulose in order to reduce the levels of waste that is generated by the common materials because this cellulosic material is considered sustainable and renewable. The development of the products was proposed through the ARZ methodological route that places the sustainability criteria as the starting and ending axis at the moment of reflecting the need, ideation, sale, use, and obsolescence of the new product. Consequently, a biomaterial is obtained with physicochemical and mechanical characteristics that allowed its application in three series of products: footwear, handbags, and costume jewelry. Sustainability is the option of the new productive thought of the design, as well as the designers; that means, creating with social and environmental responsibility.

\section{Keywords}

Bacterial cellulose, biomaterials, ethical design, product design, sustainable design. 


\section{Introducción}

La presente investigación se refiere a la posibilidad de usar la celulosa bacteriana o kombucha. Esta es obtenida en la fermentación aeróbica de un inóculo de kombucha con infusión de té y cáscaras de café, una y otra vez, como medida para la obtención de un material amigable al medio ambiente y sea parte del proceso de sustentabilidad. Este biopolímero que se degrada con el tiempo es parte de la materia prima que se usa en el diseño para la elaboración de productos en general o específicos, de forma que el material al ser biodegradable se descompondría con facilidad y sería parte de la solución a los problemas de contaminación ambiental.

En la actualidad los productos de moda, utilitarios, accesorios, entre otros, están elaborados y construidos en diferentes materiales, cuyas materias primas proceden de la extracción de minerales, pieles de animales, 0 a base de plásticos que se obtienen del petróleo. Estos materiales en el ciclo de vida del producto representan un factor determinante en la contaminación ambiental, ya sea en la obtención del material, como en su desintegración al momento de terminar su vida útil (Barzola, et al., 2018).

Por ejemplo, en el tratamiento y procesado de pieles y cueros de animales, sus aguas residuales contienen contaminantes debido a su propia desintegración, así como a la presencia de productos químicos utilizados en la preparación, curtido y teñido, a más de los residuos sólidos y emisiones a la atmósfera que dan origen a un notable impacto sobre el medio ambiente (McCann, 2010). En cuanto al plástico proveniente del petróleo, el gran problema es que la mayoría de los plásticos sintéticos no pueden ser degradados por el entorno: ni se oxidan ni se descomponen con el tiempo. A pesar de que estos han dado lugar a un gran desarrollo industrial (Chávez \& Hernández, 2018), la eliminación de los plásticos representa un grave problema medioambiental (Perdomo, 2002), ya que en función de sus componentes existe una resistencia a la degradación, por lo tanto existe una acumulación y por lo tanto, un problema de contaminación al medio ambiente, mientras que un residuo orgánico podría demorarse cuatro semanas aproximadamente y además ser usada como abono (Zeenat, Elahi, Bukhari, Shamim, \& Rehman, 2021).

La Organización Mundial de la Salud (OMS, 2017) reconoce que la contaminación ambiental ha alcanzado proporciones que alarman, arrojan estadísticas indicando que 9 de cada 10 personas respiran aire tóxico y 7 millones mueren cada año, por polución ambiental y doméstica. En Ecuador los problemas ambientales si bien han demostrado avances, por aplicación de normativas y nuevas prácticas, estas no han sido suficientes, varios de estos han sido arrastrados desde tiempo atrás y han permanecido en el tiempo (Puentestar, 2015). Existen altos índices de contaminación por descargas de efluentes industriales y domésticas; se observa contaminación del aire por elevadas emisiones industriales, uso de plaguicidas y fertilizantes; la afectación de suelos se da por malas prácticas pecuarias, explotación minera, extracción de petróleo; la problemática ambiental en la biodiversidad más común es la alteración del clima y la migración de especies entre otros (Puentestar, 2015).

La Provincia de Tungurahua se encuentra actualmente reconocida como una de las zonas de mayor importancia económica en el Ecuador, la actividad manufacturera es la base de la industria (Coello, 2016), entre las más fuertes se encuentran las curtiembres, quienes aportan a la economía local y nacional, representan 75,6 \% del aporte según Senplades (2015). La producción de pieles genera efectos negativos al medio ambiente, en los componentes: aire, por los olores, partículas del material, humo y gas; en cuanto al agua, presenta alta concentración de carga orgánica, con sustancias como estiércol, sangre, sal barro, ácidos, residuos alcalinos entre otros, que son arrojados a vertientes de aguas residuales, ríos o quebradas (Guajala, 2016).

En la actualidad el uso de biomateriales se presenta como una opción. Alrededor de los años 80 se empezó con la investigación y desarrollo de estos como parte de los avances médicos, donde se centra la mayor cantidad de experimentación y desarrollo. Existe una gran variedad de estudios enfocados a los 
reemplazos de tejidos o cubrimientos de piel humana en restauraciones, incidencia de enfermedades cardiovasculares, neurológicas y ortopédicas (Wong-Hernández, 2019), implantes dentales, sustituto temporal de la piel en tratamientos de heridas, quemaduras o úlceras, entre otros (Pineda, Mesa \& Riascos, 2012) además, en el área de la electrónica y combinando con la celulosa vegetal en producción de papel, tratamientos cosmetológicos y moda (Santos, et al, 2014; Hussain, Sajjad, Khan, \& Wahid, 2019). En el campo del diseño de productos, los biomateriales han empezado a generar un alto impacto, con el desarrollo de la celulosa vegetal en su mayor experimentación, con casos como: estudios de la cáscara de naranja, procesos físico-químicos de sus propiedades, análisis y provecho de la cáscara de coco, de las hojas de piña, biopolímeros a base del almidón de yuca entre otros (García, 2014). Sin embargo, la idea de la celulosa bacteriana está en un proceso constructivo y de análisis en el desarrollo del material para su óptima aplicación.

La investigación de esta problemática se realizó por el interés de conocer el alcance de aplicación de este nuevo material llamado celulosa bacteriana, dar valor agregado a los residuos agrícolas como la cáscara del café, dar otras oportunidades a los artesanos y contribuir a la disminución de la contaminación ambiental. En el marco del diseño, se empleó la metodología ARZ (Alvarado, Roa \& Zuleta, 2016), que articula criterios y elementos de la ecología industrial, ciclo de vida del producto, consumo sostenible y el ecodiseño, que a través de consideraciones cíclicas permiten formular la idea, producción, uso y desuso del producto.

De esta manera, el objetivo del presente trabajo consistió en aplicar celulosa bacteriana en el desarrollo de nuevos productos para el posible incremento de su uso en la industria del diseño. Se presenta al nuevo material como una opción en la industria manufacturera, industrial y artesanal tungurahuense y ecuatoriana, como aporte a las acciones a favor del cuidado del medio ambiente y como parte de la responsabilidad ética que debe tener el diseñador en el cuidado del medio ambiente.

\section{Un camino a la sustentabilidad}

El modelo del desarrollo socialmente sustentable incorpora las dimensiones de la sustentabilidad: ecológica, económica y social, convergen en un eje central denominado "desarrollo humano", este proceso ofrece a las personas mayores oportunidades, que incluyen una vida prolongada y saludable, educación y acceso a los recursos necesarios para tener un nivel de vida decente, además de oportunidades las cuales están la libertad política, la garantía de los derechos humanos y el respeto así mismo. Incorpora varios criterios de conservación del equilibrio en la relación funcional entre las dimensiones de la sustentabilidad y las consideraciones ambientales. Se preocupa del uso de materiales de bajo impacto ambiental, reducción del uso de materia prima, incorporación de energías alternativas en los procesos de producción (PNUD, 2000).
Otro de los criterios se encuentran la optimización de sistemas de distribución, reducción del impacto durante el uso del producto, duración del producto y el final de su ciclo de vida. El diseño, como actividad da origen a los objetos, productos, servicios o procesos que responden a las necesidades planteadas por la sociedad y es ejercido en su nivel básico de actuación. El modelo de desarrollo socialmente sustentable parte de la correspondencia análoga de los elementos que conforman la interfaz del diseño: usuario-producto-contexto, agregado a las dimensiones de la sustentabilidad: social-económica-ecológica, para mostrar la acción del diseño en la generación de nuevas soluciones sustentables que aporten de forma integral al desarrollo humano. La dimensión social se vuelve relevante para el diseño, ya que es el elemento vivo y dinámico del sistema y de la propia interfaz del diseño (Profile, 2016). 
Además, se considera la sustentabilidad como una estrategia que permite el desarrollo responsable y competitivo, de adelanto económico y social que cumple las necesidades y virtudes de los grupos de interés, contemplando las opciones hacia el futuro y reservando los recursos naturales. En función del consumo excesivo del planeta, se sitúa la estrategia de la sustentabilidad como una solución al problema de raíz, pues genera un equilibrio económico, ecológico y social, en una relación estrecha entre la empresa y el cliente (Díaz, 2011).

Actualmente, el diseñador cuenta con herramientas prácticas como metodológicas, es necesario ponerlas en la práctica de su quehacer diario, aún con las interrogantes que nos quedan referentes al uso de la tecnología, ¿serán suficientes para encarar el problema de la sostenibilidad?, para responder sería conveniente hablar de la ética como principio del ser humano y si expresa una condición de diferenciación entre el bien y el mal; Maliandi (2006) expresa que "debería existir una ética compensatoria para frenar nuestras capacidades destructivas" (en Zito, 2014, p. 104).

Partiendo de la premisa que otorga Zito (2014) "que el diseño sustentable es principalmente un problema ético más que técnico" (p. 104), obliga a repensar en el desarrollo de una sociedad y producción basada en principios de sustentabilidad. Los materiales biodegradables, entre otros la celulosa bacteriana, otorgan una oportunidad a la dimensión ambiental, ecológica y económica.

\section{Celulosa bacteriana}

La celulosa bacteriana (CB) es un biomaterial biodegradable (Schröpfer, et al., 2015), que ha sido estudiado y desarrollado por áreas de investigación química y biológica, este nuevo material responde a las necesidades sociales por sus excelentes propiedades mecánicas, de bajo costo, además y lo más importantes sostenibles y amigables con el medio ambiente (Hussain, Sajjad, Khan, \& Wahid, 2019). La celulosa bacteriana es una fibra natural, se la considera como un sustituto a la celulosa vegetal, que es obtenida por la tala de árboles la cual es causante de la problemática creciente de la deforestación (Nava, 2016).

El biomaterial (CB) es producido por una bacteria gram-negativa denominada Acetobacter xylinum, reclasificada como Gluconacetobacter xylinuse y considerado como modelo de estudio (Steinbüchel, 2005). Brown (1886) la definió como una "membrana gelatinosa traslúcida que crece en la superficie del medio de cultivo" (en Nava, 2016, p. 9). Esta fibra tiene más de 100 años de investigación previa, y su estudio ha ido incrementándose cada vez más, ello lo demuestra el número de patentes que se han registrado los últimos 40 años. 
Figura 1. Evolución del número de patentes anual en celulosa bacteriana

115 90
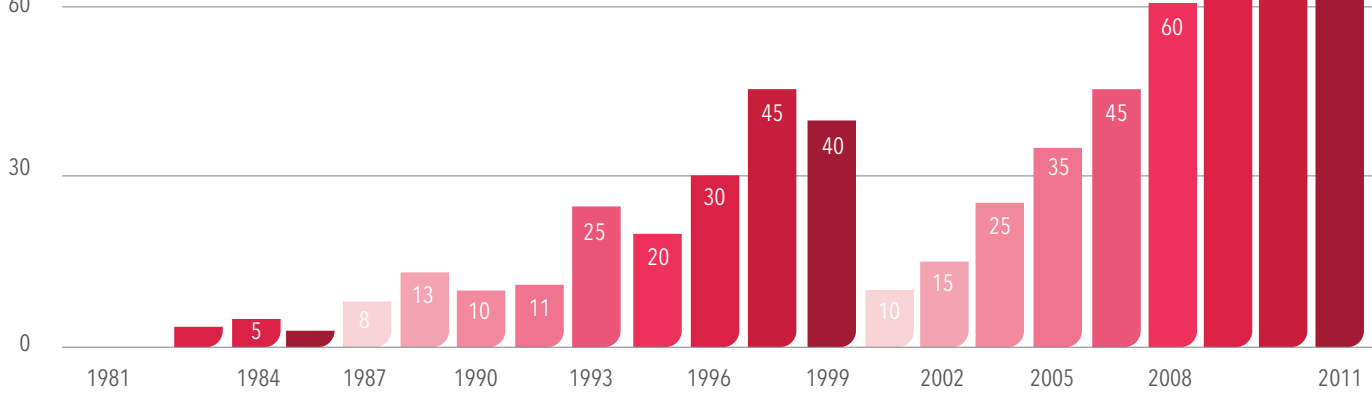

De Nava, (2016).

Este material es atractivo por las propiedades que presenta y las diferentes aplicaciones que se podrían llegar a producir. Se la considera elástica y con alta resistencia a la tracción, debido a su distribución en retícula que brinda un índice de cristalinidad entre 60 y $70 \%$ y un área superficial disponible hasta 200 veces mayor que la vegetal (Carreira, et al., 2011; Hussain, Sajjad, Khan, \& Wahid, 2019) según Ramírez (2020) "esta membrana está constituida por una red de cintas de tamaño nanométrico, responsables de su buen comportamiento mecánico y sus propiedades fisicoquímicas" (p. 8). 
Figura 2. Propiedades de la celulosa bacteriana

\begin{tabular}{|l|}
\hline Alto grado de cristalinidad \\
\hline Mayor área de superficie que la pulpa de madera convencional \\
\hline Densidad de hoja de 300 a $900 \mathrm{~kg}^{\star} \mathrm{m}-3$ \\
\hline Alta resistencia a la tracción \\
\hline Alta absorbencia \\
\hline Alta elasticidad y durabilidad \\
\hline No tóxico \\
\hline Inactividad metabólica \\
\hline Biocompatibilidad \\
\hline Susceptible a la degradación \\
\hline Gran retención de forma \\
\hline Fácil adaptación a las propiedades fisicoquímicas \\
\hline
\end{tabular}

De Nava, (2016).

Es necesario acotar que la celulosa bacteriana tiende a modificarse al agregar componentes al cultivo, derivados de la celulosa como: ácidos sulfónicos, fostfatos de alquilo y otros polisacáridos, alteran la morfología macroscópica lo que permite potenciarla, en cuanto al color, resistencia a la tracción, brillo entre otros (Steinbüchel, 2005; Hussain, Sajjad, Khan, \& Wahid, 2019).

\section{Metodología}

La investigación tiene carácter experimental, en el desarrollo de un nuevo material y la aplicación de la ruta metodológica ARZ, la cual, está basada en los criterios de sustentabilidad, con base teórica en las metodologías proyectuales de: Ambrose - Harris, Paul Rodgers y Alex Milton, Bruno Munari, Gerardo Rodríguez, Nigel Cross, Fundación Prodintec (Alvarado-Nieto, Roa-López, \& Zuleta-Ortíz, 2016) 
Figura 3. Metodología de diseño ARZ, para objetos sostenibles

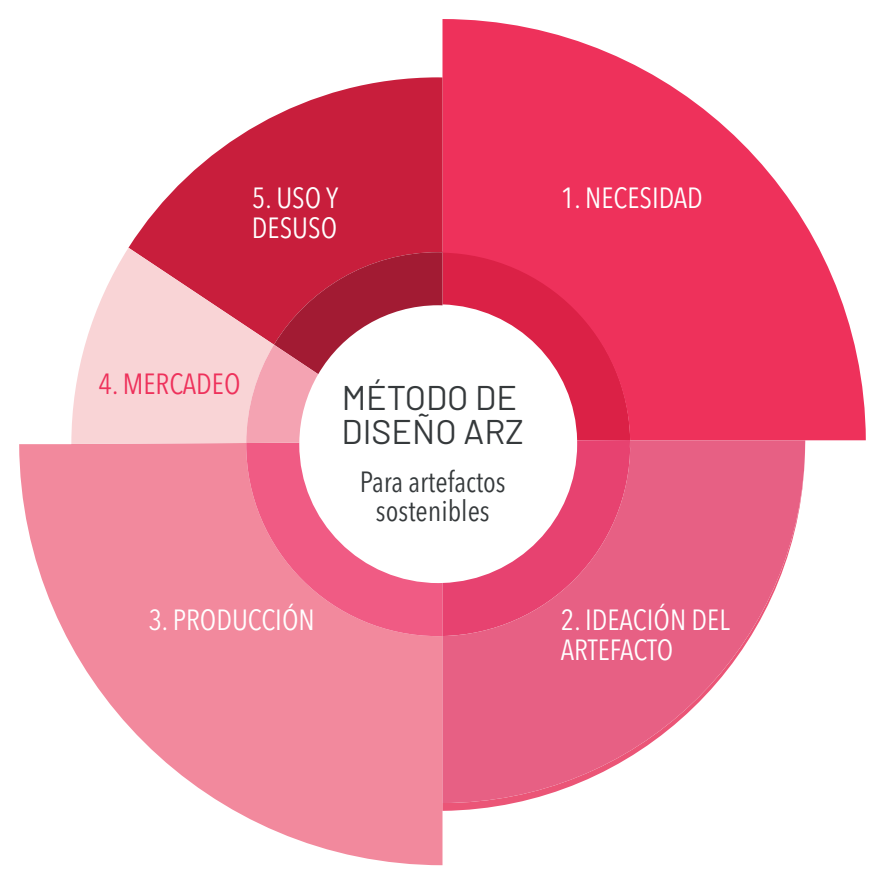

De Alvarado-Nieto, (2016).

Necesidad: Desarrollo del nuevo material o celulosa bacteriana

Para la realización de la membrana a usar en la cartera, zapatos y accesorio, se siguió el método establecido por Schramn \& Hestrin (1954) con ligeras modificaciones. Par (Schramn \& Hestrin, 1954) a ello, se preparó un medio de cultivo a base de la infusión de té negro (Hornimas, Cetca, Ecuador) (25\%) y cáscara de café Arábigo variedad caturra que provino de la ciudad y provincia de Loja $(75 \%)$ de una masa de $8 \mathrm{~g} / \mathrm{L}$ de hojas y cáscara; y azúcar (Marca Valdez S.A., Ecuador) (5\%) de la infusión. Se usaron seis biorreactores de plástico, de aproximadamente $32 \mathrm{~L}$ de $42 \star 35 \mathrm{~cm}$ de capacidad. Se sembró en cada biorreactor un inóculo inicial de Kombucha, en el medio estéril y fue mantenido durante 10 días entre 28 a $30{ }^{\circ} \mathrm{C}$ a pH 3,5. Pasado este tiempo, las membranas de celulosa fueron cosechadas, lavadas con agua caliente a $80 \mathrm{oC}$, desinfectadas con hipoclorito de sodio a $2 \%$, secadas a $28 \pm 3{ }^{\circ} \mathrm{C}$ y revestidas con glicerina y resina hidrofóbica para su posterior uso.

Las membranas obtenidas fueron analizadas en el espesor con un micrómetro digital Mitutoy modelo TPM-H-2781 con rango de medición de $0,001 \mathrm{~mm}$ hasta $12,7 \mathrm{~mm}$ a través de 10 mediciones, cuyo resultado es la media de ellas. La fuerza de tracción se realizó a través de la norma ASTM D182-18 en la máquina Universal Shimadzu modelo AGS-J, para ello se realizaron probetas de $20 \mathrm{~cm}$ de largo por 2,5 cm de ancho. La textura se evaluó a través de observaciones directas. Finalmente, para evaluar la resistencia al calor, la membrana de CB fue sometida a una plancha de calentamiento cuya medición fue la temperatura que producía algún cambio.

El proceso de obtención se desarrolló de forma repetida, la tintura se logró con la combinación de materiales orgánicos y artificiales como: remolacha, tinte vegetal azul, y tinte vegetal amarillo. 
1. Ideación del artefacto

Bocetaje de productos: Se escogió tres tipos de accesorios de indumentaria cómo: Calzado, cartera y bisutería. Se realizaron varios bocetos, pasa a un proceso de selección por forma y proceso constructivo, que permita la experimentación del uso del material.

\section{Producción}

Aplicación de la celulosa en el diseño de productos: La producción de los objetos se realizará en diferentes talleres. La línea de calzado con la diseñadora Patricia Montegro; la línea de bolsos en el taller del diseñador Gabriel Núñez; la bisutería será elaborada por la autora de esta investigación.

Se realizará un levantamiento de información, respecto al uso del material por parte de los diseñadores antes mencionados.

\section{Mercadeo venta}

Marca: Se construyó una marca, que identifique nuevos productos con características biodegradables, que permitan competir en el mercado actual, y obtenga una clara identidad del producto. Además, a fin de conocer el interés a nivel local y nacional, se realizó un levantamiento de información a través de encuestas a una muestra de 278 personas, entre los 16 y 40 años.

\section{Uso y desuso}

Post consumo: Los productos tienen la opción de separar las partes, y de forma amigable con el medio ambiente cada parte puede ser desechada con una baja probabilidad de contaminación al medio ambiente.

\section{Resultados}

Necesidad: Se obtuvieron 6 membranas de celulosa bacteriana seca de aproximadamente $30 \times 40 \mathrm{~cm}$ por 0,24 mm de espesor con $68 \mathrm{MPa}$ de fuerza de tracción, tolerancia al calor hasta $150{ }^{\circ} \mathrm{C}$. Estas membranas fueron flexibles y fáciles de trabajar debido al tratamiento posterior al secado de humectación que se les dio y de impermeabilización. Se obtuvieron rendimientos de $18,7 \mathrm{~g} / \mathrm{L} / \mathrm{d}$ de celulosa. Se obtuvieron membranas de CB de diferentes colores como amarillo, rojo, azul entre otros. 
Figura 4. Proceso de obtención del material

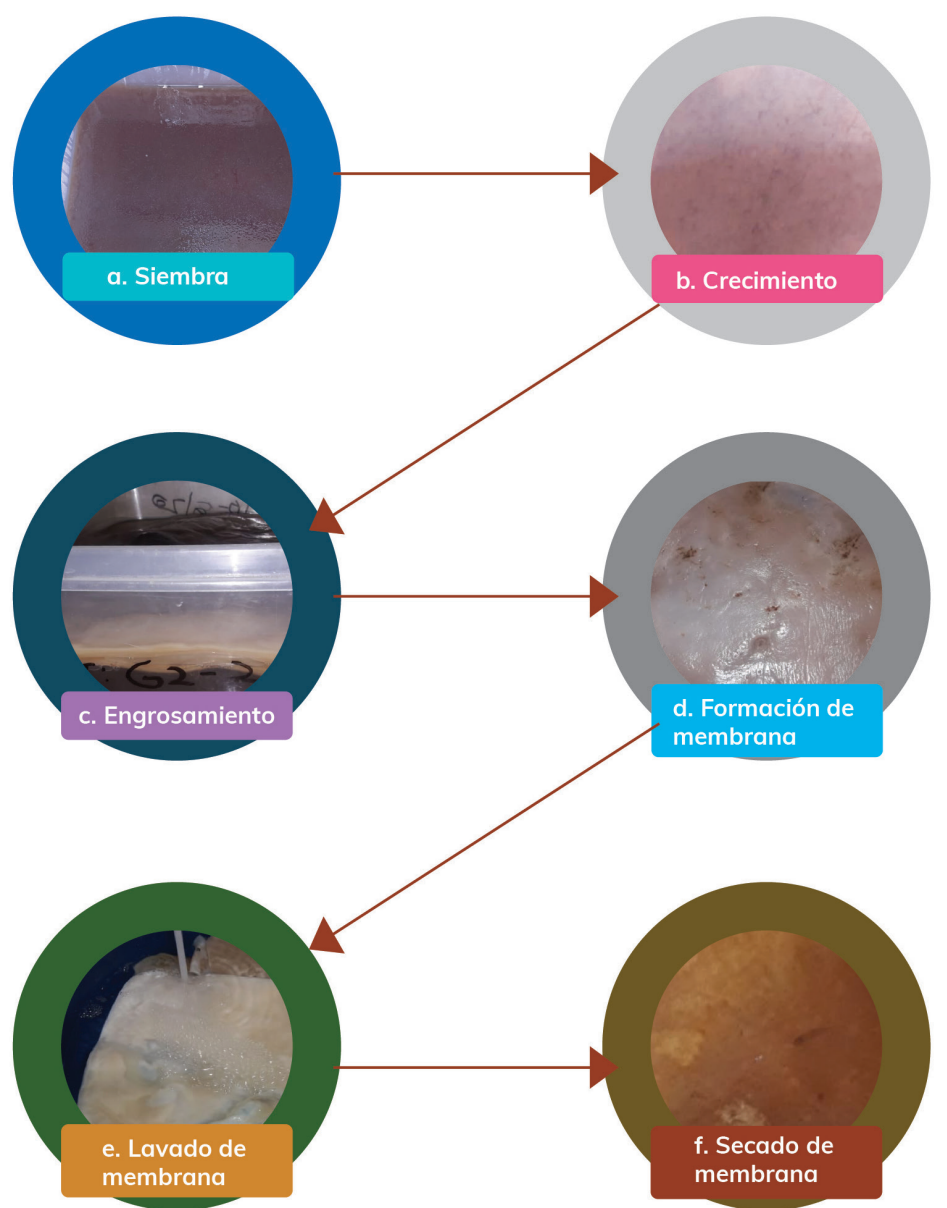

Se consiguió variedad de material en tamaño, color, textura y grosor, como pruebas experimentales, sin embargo, ya con el método mencionado en la metodología, se realizó la siembra de manera simultánea para la obtención del material y posterior aplicación. Las medidas promedio son de $30 \times 40 \mathrm{~cm}$.

Requerimientos técnicos: Entre los requerimientos técnicos que se deben considerar al momento de trabajar con la celulosa en el desarrollo de productos son:

- Trabajo en frío, puesto que no resiste temperaturas mayores a 150 grados celsius.
- La celulosa permite la unión de las láminas a través de superposición en húmedo, la línea de unión se pierde en el proceso de secado.

- Permite el cosido entre láminas y con otros materiales como cuero o tela.

- Los cortes se pueden realizar con tijera 0 cuchilla.

- Usar pegamentos fríos.

- Guardar el material o los productos en áreas secas.

- La limpieza se puede realizar con paños secos.

- No humedecer el material o producto. 
Figura 5. Celulosa bacteriana en proceso de pigmentación y secado

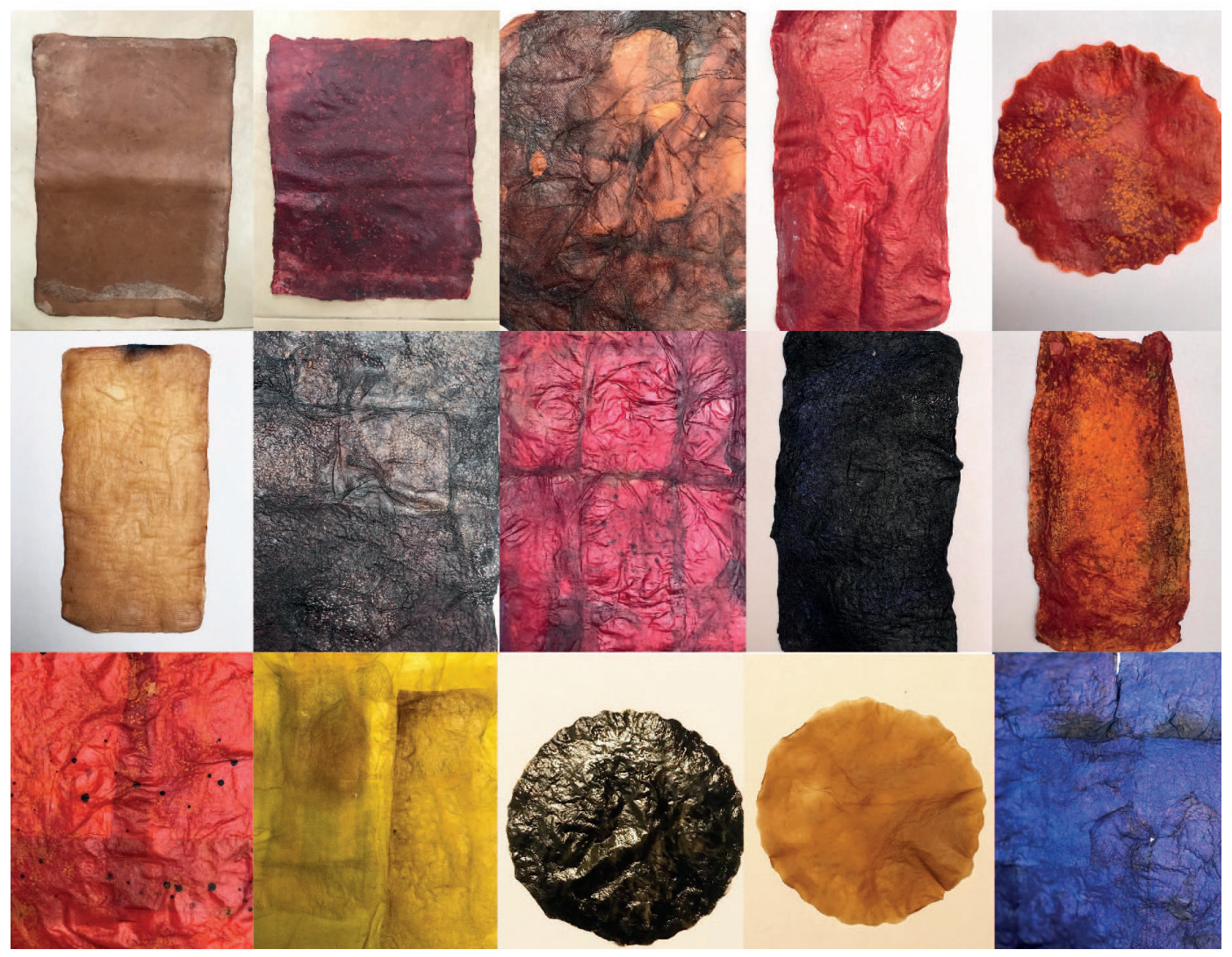

\section{Ideación}

Figura 6. Proceso de bocetaje para el diseño de calzado
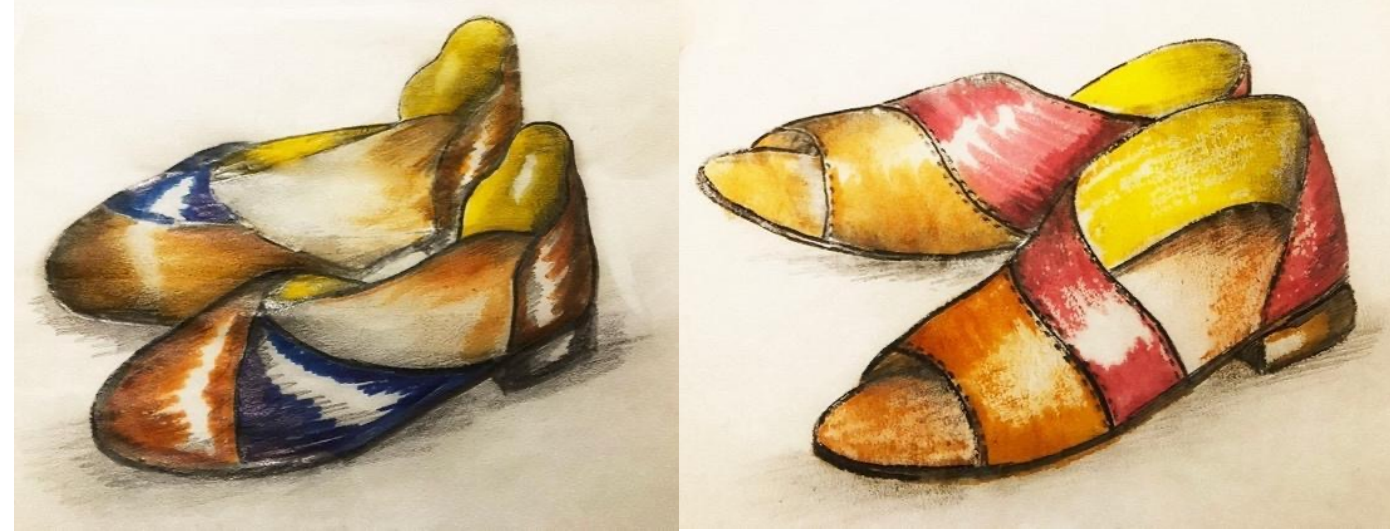
Figura 7. Proceso de bocetaje para el diseño de carteras
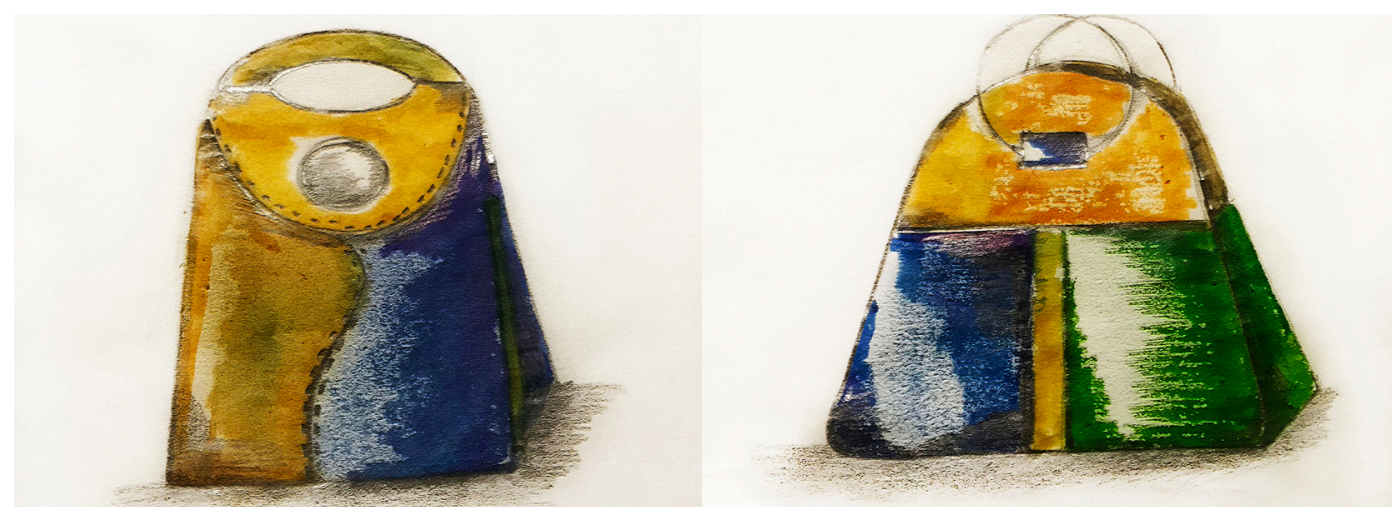

Figura 8. Proceso de bocetaje para el diseño de bisutería
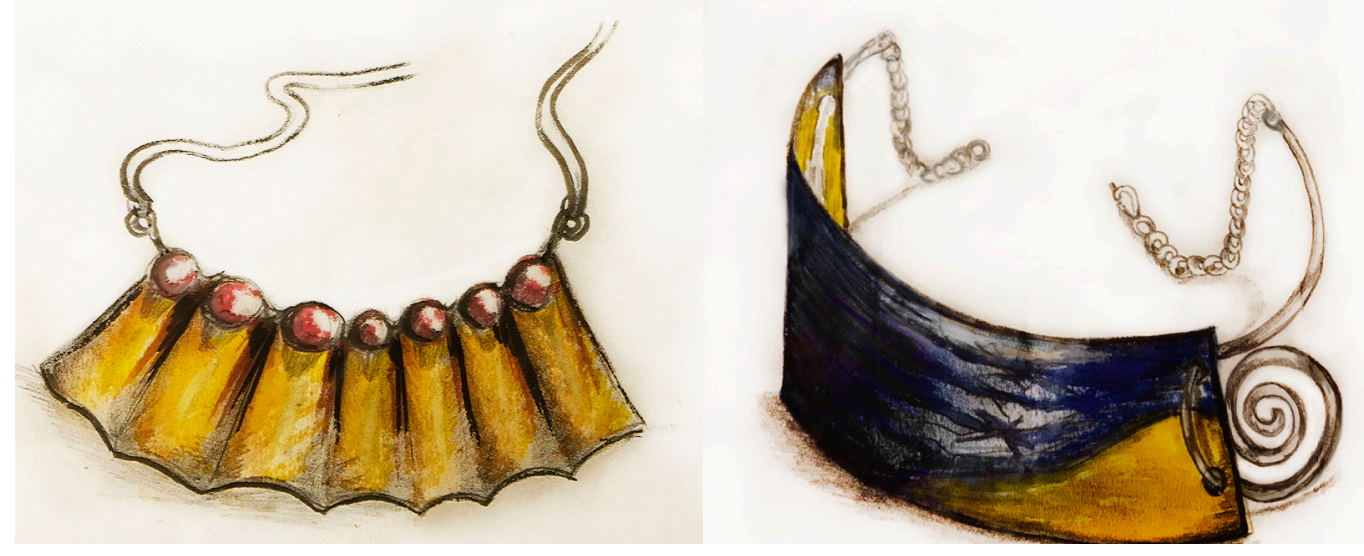


\section{Producción}

Tabla 1. Ficha del producto. Calzado

\begin{tabular}{|l|l|}
\hline \multicolumn{1}{|c|}{ Ficha de producto } & \multicolumn{2}{|c|}{ FP: 001} \\
\hline Nombre: Calzado & Detalle: \\
\hline Registro Fotográfico: Producto final & \\
\hline
\end{tabular}


Tabla 2. Ficha del producto. Cartera

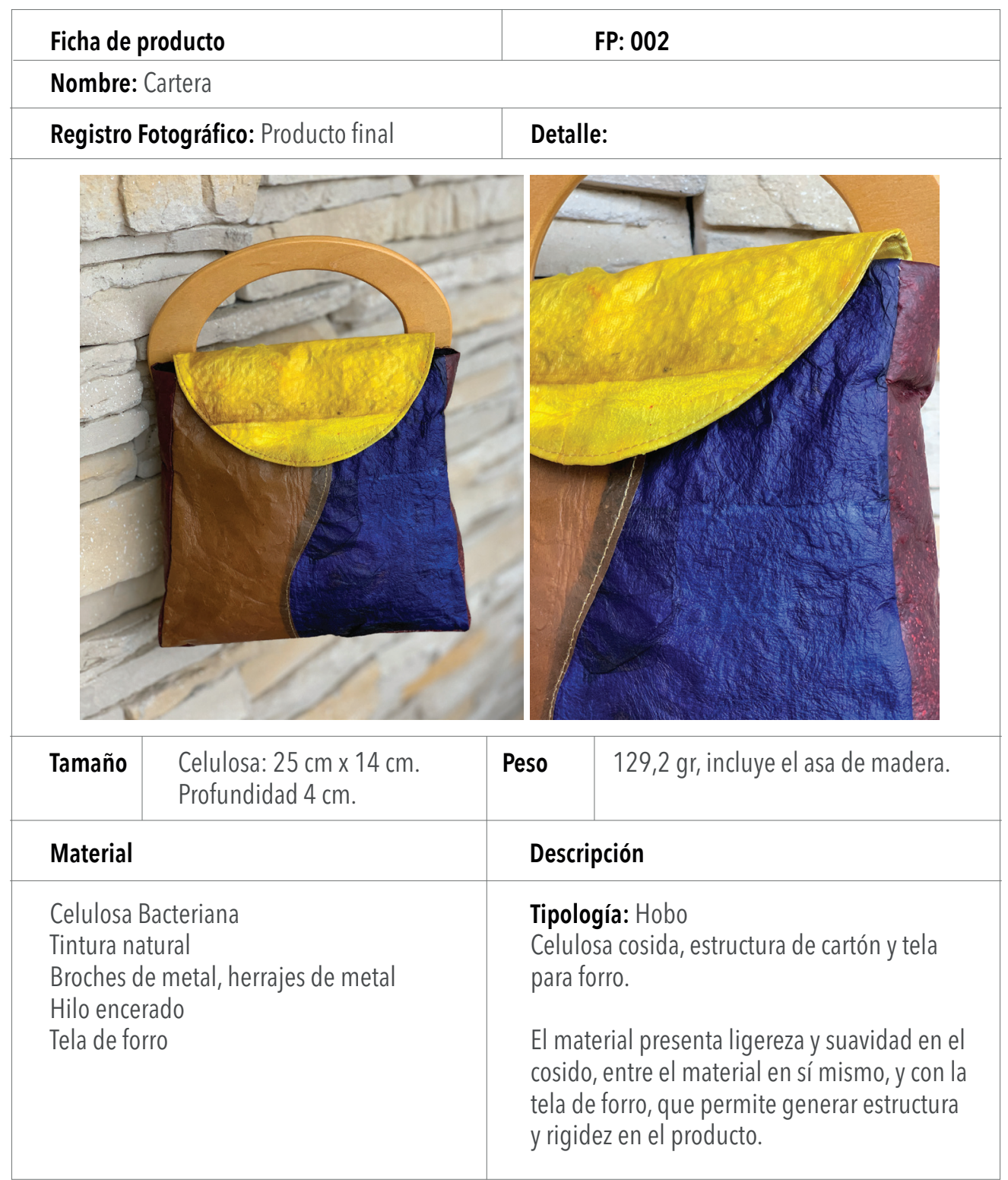


Tabla 3. Ficha del producto. Bisutería

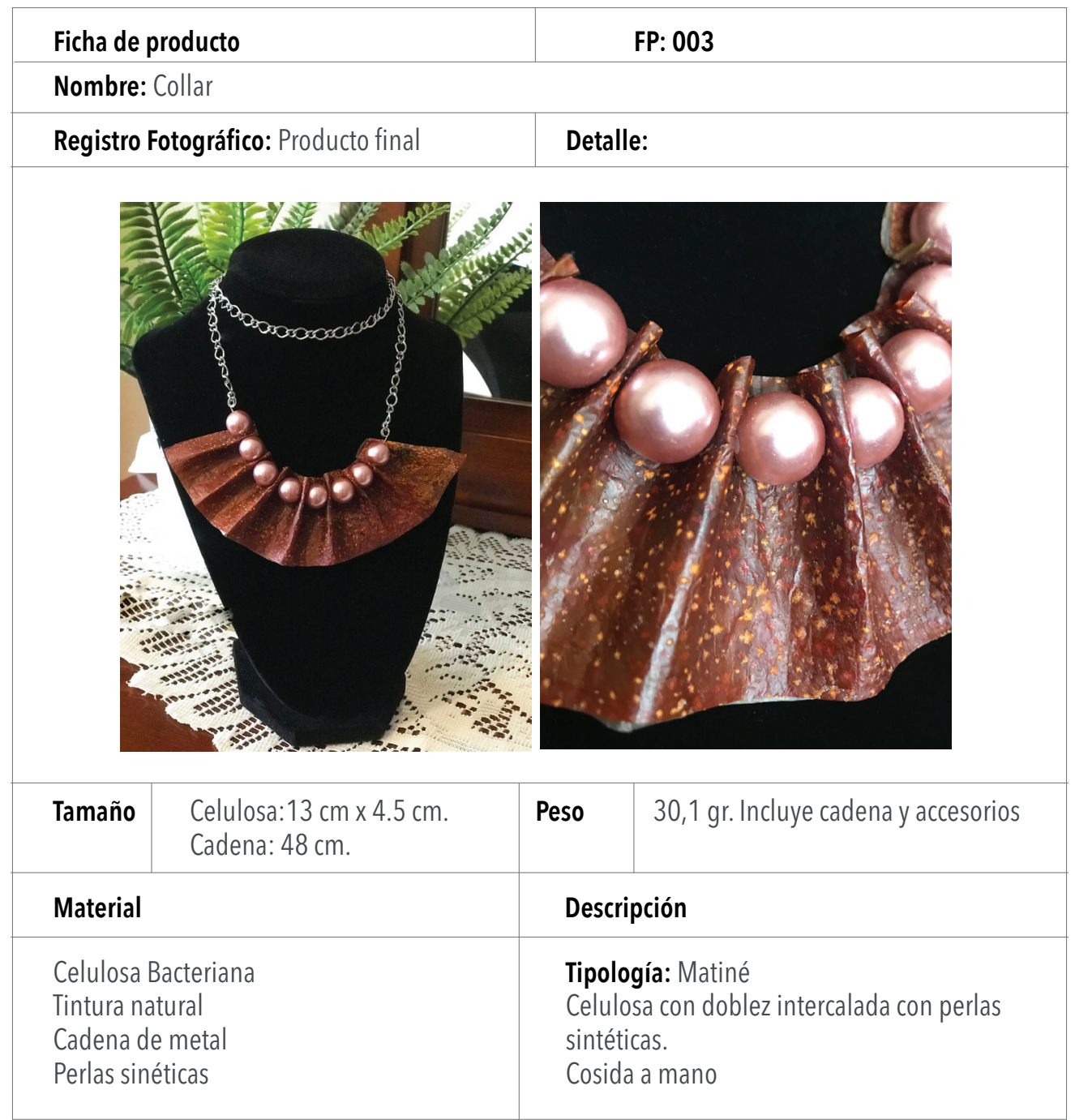

Desarrollo de la marca: La marca que se desarrolló para el nuevo producto, resultado de la aplicación de la celulosa bacteriana se denomina, Suyana, cuyo significado es esperanza en la lengua quechua. La marca permite nombrar y etiquetar al producto, con la visión de generar un posicionamiento en el mercado del diseño de producto. 
Figura 9. Diseño de marca "Suyana"

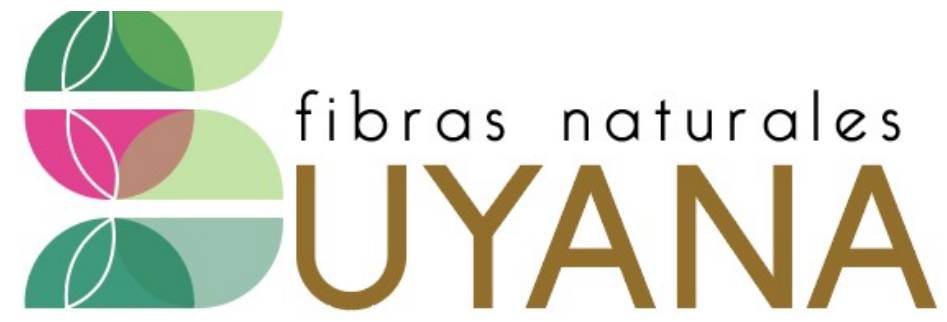

Uso y desuso

Post consumo: Cada producto ha sido desarrollado con varios componentes, la materia prima con mayor porcentaje de uso es la celulosa, sin embargo, tiene otros materiales que acompañan la fabricación; por ello lograr la separación de las partes permitirá el correcto desecho de los mismos. En el caso de la celulosa, está puede ser parte de la basura orgánica para compost, u otro proceso de desecho.

\section{Conclusiones}

La aplicación de la celulosa bacteriana es una posibilidad en el desarrollo de productos, en un inicio a nivel artesanal, sin embargo, se necesitaría mayor profundización en la investigación para escalar a nivel industrial. Actualmente se evidencia el crecimiento de su utilización en diferentes áreas por las propiedades que brinda, además de ser un producto sustentable y renovable, aportando así al incremento del uso en el mercado de los biomateriales y siendo parte de la disminución de la contaminación ambiental.

Las propiedades de la celulosa bacteriana son una gran alternativa por su pureza, retención de agua y estabilidad mecánica. Superando las propiedades de la celulosa vegetal. Resulta un excelente sustituto a materiales como el cuero animal o plástico a nivel artesanal. Aunque las posibilidades se han experimentado de gran manera en el área de la salud, la parte industrial podría tener una gran participación con mayor experimentación y difusión del material.

Se puede obtener celulosa bacteriana con desechos orgánicos, lo que implica un costo bajo de producción. El proceso lleva tiempo y cuidado del material, sin embargo, es factible obtenerlos de forma casera 0 doméstica, permite la experimentación y la variedad de producción.

La celulosa bacteriana brinda facilidades en su manejo y aplicación, los productos que se obtuvieron resaltan la forma, función y estética del material, permite el tinturado, cambios de textura y se amolda en estado húmedo. En la fabricación de los productos se consideró las propiedades sobre todo mecánicas, en cuanto a su resistencia y tensabilidad, en especial en la fabricación del calzado. 


\section{Referencias}

Alvarado-Nieto, G. A., Roa-López, P. A., \& Zuleta-Ortíz, D. L. (2016). Formación en Diseño Industrial: una propuesta metodológica coherente con el desarrollo sostenible. Revista Interamericana de Investigación, Educación y Pedagogía-RIIEP, 163-188. https://doi.org/10.15332/ s1657-107x.2016.0001.09

Bernatene, M., Canale, G. (2018). Cuaderno 69 Presente y futuro del diseño latino. Cuadernos Del Centro de Estudios En Diseño y Comunicación, (69), 151-174. Recuperado de: https://fido. palermo.edu/servicios_dyc/publicacionesdc/archivos/663_libro.pdf

Carreira, P., Mendes, J. A. S., Trovatti, E., Serafim, L. S., Freire, C. S. R., Silvestre, A. J. D., \& Neto, C. P. (2011). Utilization of residues from agro-forest industries in the production of high value bacterial cellulose. Bioresource Technology, 102(15), 7354-7360. https://doi.org/10.1016/j.biortech.2011.04.081

McCann, M. (2010). Cuero, Pieles Y Calzado. Enciclopedia De Salud Y Seguridad En El Trabajo, 14. http://www.insht.es/InshtWeb/Contenidos/Documentacion/TextosOnline/EnciclopediaOIT/tomo3/88.pdf

Nava, M. G. (2016). Diseño de planta piloto para producción de Celulosa Bacteriana. Escola Tècnica Superior d'Enginyeria Industrial de Barcelona.

Perdomo G. (2002). Plásticos y medio ambiente. Revista Iberoamericana Polímeros Volumen 3(2), 1-13. http://www.ehu.eus/reviberpol/pdf/abr/perdomo.pdf

Profile, S. E. E. (2016). Proyectos productivos. El diseño en la dimensión social. (September 2013).

Puentestar Silva, W. P. (2015). La problemática ambiental y el deterioro de los recursos naturales en el Ecuador. Una perspectiva desde la geografía (Bachelor's thesis, PUCE).

Schramn, M., \& Hestrin, S. (1954). Factors affecting production of cellulose at the air/liquid interface of a culture of Acetobacter xylinum. Journal of General Microbiology, 11(1), 123-129. https://doi.org/10.1099/00221287-11-1-123

Schröpfer, S. B., Bottene, M. K., Bianchin, L., Robinson, L. C., De Lima, V., Jahno, V. D., Da Silva, H., Lima, S. J. (2015). Biodegradation evaluation of bacterial cellulose, vegetable cellulose and poly (3-hydroxybutyrate) in soil. Polimeros, 25(2), 154-160. https://doi.org/10.1590/01041428.1712

Zeenat, Elahi, A., Bukhari, D. A., Shamim, S., \& Rehman, A. (2021). Plastics degradation by microbes: A sustainable approach. Journal of King Saud University - Science, 33(6), 101538. https://doi.org/10.1016/j.jksus.2021.101538

Zito, M. (2019). La ética del diseño sustentable. Cuadernos Del Centro De Estudios De Diseño Y Comunicación, (48), 95 a 105. https://doi.org/10.18682/cdc.vi48.1380 